\title{
Bed-parallel slip: Identifying missing displacement in mass transport deposits
}

G.I. Alsop ${ }^{1}$, R. Weinberger ${ }^{2,3}$, S. Marco ${ }^{4}$, T. Levi ${ }^{2}$.

1) Department of Geology and Geophysics, School of Geosciences,

University of Aberdeen, Aberdeen, UK. (e-mail: Ian.Alsop@abdn.ac.uk)

2) Geological survey of Israel, Jerusalem, Israel.

3) Department of Geological and Environmental Sciences, Ben Gurion University of the Negev, Beer Sheva, Israel.

4) Department of Geophysics, Tel Aviv University, Israel.

\section{Abstract}

Bed-parallel slip (BPS), where neighbouring beds slide past one another along bedding planes, is notoriously difficult to identify without reference to pre-existing features such as steep faults or dykes that act as markers to record BPS offset. While BPS is intuitively thought to operate during downslope sliding of mass transport deposits (MTDs) in sedimentary basins, there is a conspicuous lack of supporting outcrop or seismic data to corroborate this and BPS displacement may therefore have remained unaccounted for. This study addresses this gap in knowledge by investigating late-Pleistocene MTDs developed around the Dead Sea Basin and provides the first detailed analysis of BPS that pervades a gravity-driven setting. In particular, we examine the role of BPS that crosscuts earlier normal and reverse faults that act as markers to allow metre-scale patterns of horizontal displacement to be identified in MTDs. The studied BPS always forms with a consistent top-to-the east sense of offset that corresponds with gravity-driven downslope movement towards the depo-centre of the basin. BPS frequently develops adjacent to competent detrital-rich beds and forms discrete glide planes with little or no visible deformation in sediments on either margin, although detachment folds are occasionally developed above the slip plane and confirm directions of easterly movement. Early downslope-dipping normal faults that are cut by later BPS planes results in older over younger stratigraphic relationships across the BPS surface, together with 'sawtooth' patterns where multiple BPS planes have developed. Conversely, early upslope-dipping normal faults that are cut by BPS create younger over older stratigraphic relationships combined with missing section and 'staircase' patterns where multiple BPS planes exist. As BPS in subhorizontal sequences does not have a vertical component of displacement, it may be examined in terms of horizontal 'heave'. BPS increases heave in upslope-dipping normal faults, whereas it reduces heave in downslope-dipping normal faults and may even become negative where sections are repeated across sawtooth profiles. In addition, BPS increases heave in upslope-dipping reverse/thrust faults and reduces heave across downslope dipping 'backthrusts'. Although individual BPS planes may have limited displacement, the net consequence of multiple planes of BPS that form in the shallow-subsurface is to distort patterns and estimates of extension and contraction across fault zones in MTDs.

Keywords: Bed-parallel slip; mass transport deposits; Dead Sea

\section{1) Introduction}

Bed-parallel slip (BPS), where adjacent beds slide past one another along discrete bedding planes is almost impossible to recognise at outcrop without the benefit of steep cross-cutting structures, such as discordant dykes or faults, that create markers which indicate the magnitude of subsequent BPS displacement. Heim (1878) is considered the first to describe BPS in multilayer sequences, and since then it has been reported from a range of settings which invoke a variety of mechanisms (see Delogkos et al., 2018 for a recent review). We here provide only a very brief summary and note that flexural-slip is considered perhaps the most widespread mechanism to generate BPS across a range of scales (e.g. 
Chapple and Spang, 1974; Ramsay, 1974; Tanner, 1989; Watterson et al., 1998). Flexural-slip folding results in variably dipping beds around the fold, with the amount of associated BPS increasing towards the fold limbs and reducing towards the hinge of the fold (e.g. Fossen, 2016, p.271). Such a mechanism is typically recorded by displaced markers such as clastic dykes around decametric scale folds in California (e.g. Palladino et al. 2016) or via bedding-parallel quartz veins that display inclined fibres created during syn-tectonic veining and growth of fibres (e.g. Fowler and Winsor, 1997). Delogkos et al. (2017, 2018) describe displaced normal faults that define BPS geometries from quarried faces in a lignite mine in NW Greece, where hangingwalls above BPS planes move up the regional dip and therefore indicate flexural slip associated with underlying basement faults.

Alternatively, BPS associated with flexural shear folding above listric extensional faults has also been suggested by Higgs et al. (1991). They describe Neogene-aged faulting from Utah, in which early steep normal faults are cut by later BPS along weak mudstone horizons created during extensional toptoward-the master fault 'rollover'. Layer-parallel shear along discrete bedding planes that results in the offset of pre-existing normal faults has been recorded during Miocene-aged deformation in Nevada (Ferrill et al., 1998). Normal faults and BPS may have been active simultaneously during rotation of large blocks above the extensional detachment system (Ferrill et al., 1998). Finally, BPS is considered to operate in salt diapirs where displacement along steeply-dipping beds of salt results in offset of an overlying dissolution surface that acts as a horizontal marker in the Sedom salt wall of the Dead Sea Basin (e.g. Zucker et al., 2019). Given this range of settings that BPS has been identified in, it is perhaps unsurprising that it has also been suggested to occur in gravity-driven systems such as developed in offshore basinal settings (e.g. Gamboa and Alves, 2015). Indeed, based on outcrop studies, Delogkos et al. (2018, p.132) conclude that "we would expect bed-parallel slip to exist where any form of flexural-slip folding or gravitational sliding occurs, whatever their origins, but its identification might not always be possible due to the nature of the host rock sequence and the absence of suitable slip markers." Similar issues arise when working on seismic sections across gravity-driven downslope movement of sediments, with Shillington et al. (2012, p.441) noting that "it is likely that shear is more prevalent than can be identified in seismic sections since it will occur preferentially along bedding planes, and offsets may frequently be small".

Although improved seismic resolution combined with better mapping of the ocean floor have resulted in a greater appreciation of gravity-driven failure of unlithified sediment, seismic resolution still prohibits the detailed analysis of resulting structures (e.g.; Gee et al., 2006; Reis et al., 2016; Jolly et al., 2016; Scarselli et al., 2016; Ortiz-Karpf et al., 2018; Steventon et al. 2019). We follow Posamentier and Martinsen (2011, p.8) who state "The term mass transport deposit (MTD) encompasses several slope deformational processes including creep, slide, slump, and debris flow" (see also Moscardeli and Wood, 2008; Armandita et al., 2015), and as such also incoporates potential components of BPS. BPS creates bed-parallel slide planes that may simply be defined in MTDs as 'shear failure along discrete shear planes with little or no internal deformation or rotation' (Moscardelli and Wood, 2008, p.76, their fig. 2). Traditional models of slope failure suggest that the upslope head of the MTD is dominated by extension, while the downslope toe is dominated by contraction (e.g. Farrell, 1984). Such patterns have been interpreted at outcrop (e.g. Farrell and Eaton, 1987; Martinsen and Bakken, 1990; Gibert et al., 2005; Garcia-Tortosa et al., 2011; Sobiesiak et al., 2017; Jablonska et al., 2018), and in seismic sections across offshore MTDs (e.g. Zalan, 2005; Frey-Martinez et al., 2005; 2006; Moscardelli and Wood, 2008; de Vera et al., 2010; Morley et al., 2011). The general lack of detailed analysis of BPS in either the 
extensional or contractional portions of gravity-driven MTDs reflects the necessity for a) upright or discordant markers such as dykes and faults to record BPS; and, b) a laminated layer-cake stratigraphy that permits a detailed resolution of fault movements. The relative scarcity of BPS recorded to date in such settings may therefore be a consequence of these stringent observational requirements rather than the actual absence of BPS in gravity-driven systems.

In order to clarify the role of BPS in gravity-driven systems, we have performed an outcrop-based study of late-Pleistocene MTDs exposed around the Dead Sea Basin. This fieldwork-focussed approach, that examines intricately laminated lake-sediments, has the advantage that BPS structures that are rendered largely 'invisible' in other outcrops or seismics may be identified and studied in detail. This stratigraphic precision allows us to establish a range of potential overprinting scenarios where BPS transects both upslope and downslope dipping normal faults, together with thrust faults developed in the contractional toes of MTDs.

Our broad research aims are to:

i) examine and explain the geometric effects of BPS overprinting earlier normal and reverse faults;

ii) evaluate and elucidate the role of BPS in the evolution of MTDs around the Dead Sea Basin; and

iii) explore and expand on the geometric consequences of BPS in gravity-driven systems such as MTDs.

In particular, we address the following research questions linked to the identification of BPS within MTDs:

a) What potential mechanisms drive BPS?

b) Is BPS surficial or shallow sub-surface?

c) What controls the position and propagation of BPS planes?

d) What are the geometric consequences of BPS in gravity-driven systems?

\section{2) Geometric framework of BPS cutting earlier faults}

We first establish a geometric framework for the description of BPS cutting earlier normal and reverse faults in MTDs (Figs. 1,2). We stress that in these scenarios, early normal and reverse faults act as 'markers' that are cut by later BPS, with negligible reactivation of the earlier faults after BPS. Our models therefore contrast with those of Delogkos et al. (2017, p.202) that focussed entirely on BPS cutting normal faults in a flexural slip setting, with continued and intermittent reactivation of both normal faulting and BPS leading to overlapping fault segments and fault-bound lenses. We apply standard fault nomenclature to our analysis, where the vertical and horizontal components of displacement across a fault are termed 'throw' and 'heave' respectively (e.g. Fossen, 2016, p.482; Twiss and Moores, 2007 p.62). During BPS, displacement is parallel to bedding which in offshore basinal settings may be extremely low and potentially $<1^{\circ}$ (see Alsop et al., 2016). Hence, displacement associated with BPS in MTDs may be reasonably treated purely in terms of heave. This approach necessarily differs from the analysis of Delogkos et al. $(2017,2018)$ where overlapping normal faulting and BPS where best investigated via variations in fault throw.

Marker beds in which the hangingwall and footwall cut-offs across the early fault are both below the level of the later BPS plane remain geometrically unaffected by BPS (Fig. 1a). Alternatively, marker 
beds in which the hangingwall and footwall cut-offs across the early fault are both above the level of the BPS plane also remain geometrically unaffected by BPS and are simply transported passively on the underlying detachment (Fig. 1a). However, marker beds in which the hangingwall and footwall cut-offs across the early fault are separated by the intervening BPS plane result in a range of geometric scenarios depending on the direction of dip of the early fault (upslope or downslope) and if displacement along the earlier fault is synthetic or antithetic to the later BPS (for discussion of terms see Stewart and Argent, 2000).

In synthetic (downslope-dipping) normal faults, the overall horizontal marker offset (heave) is equivalent to the normal fault heave $(\mathrm{H})$ minus the BPS offset (Fig. 1a), whereas in antithetic (upslope dipping) normal faults, the overall horizontal marker offset (heave) is equivalent to the normal fault heave (H) and BPS offset combined (Fig. 1f). In synthetic normal faults, the effect of BPS is to reduce marker offset, with BPS offset > normal fault heave ultimately resulting in 'repeated section' and negative marker offset (i.e. the marker cut-off in the footwall of the normal fault now lies further downslope and above its equivalent hangingwall cut-off resulting in a 'sawtooth' profile) (Fig. 1b,c). In antithetic normal faults, the overall effect of BPS is to positively increase marker offset potentially resulting in 'missing section' across the BPS plane and a 'staircase' profile (Fig. 1f, g, h).

The effects of BPS on early faults may be reversed by performing a 'cut \& paste' restoration, whereby the hangingwall block above the BPS plane is simply moved back upslope until the earlier 'marker' fault coincides on each side of the BPS plane for synthetic faults (Fig. 1c, d) and antithetic faults (Fig. 1h, i). Although such restorations assume that the section is directly parallel to the BPS direction, and that all BPS deformation has taken place along the slip plane, it does provide a quick and effective technique to display the earlier fault geometry and acts as a guide to determine the amount of BPS offset. Such restoration is only possible due to the planar and sub-horizontal nature of the BPS surfaces, with any small apparent 'gaps' or 'overlaps' across restored BPS planes being a consequence of irregular outcrop surfaces that locally distort the photographic image, rather than genuine geological issues.

Types of marker offset (heave, throw) across the early fault plane are compared and highlighted (in green) where marker beds have subsequently been displaced by BPS (Fig. 1e, j). The correlation of displaced individual fault segments across later BPS planes is confirmed by examining the amount of throw across earlier faults that should display similar values or trends when plotted on graphs from each side of the BPS plane (Fig. 1e, j). Such graphs also illustrate how the heave of marker beds changes dramatically where BPS intervenes between the footwall and hangingwall cut-offs along the earlier fault (Fig. 1e, j). In synthetic normal faults, the heave of the marker beds has a negative value (denoted -ve) where BPS > fault heave and contractional repeated sections are produced (Fig. 1c, e). In antithetic normal faults, the heave of marker beds is increased (i.e. extensional and positive value denoted +ve) where affected by BPS (Fig. 1j). We also highlight (via green triangles) the true horizontal displacement of beds overlying the BPS plane that have been passively carried downslope when compared to the footwall sequence below the slip plane. The observation in each case that the value of throw on the normal fault systematically reduces up the dip of the fault, and does not vary significantly on crossing the BPS plane, confirms that we are correlating and comparing the same original fault that was subsequently offset by BPS (Fig. 1e, j).

We have also applied the same geometric framework and methodology to reverse faults that have been subsequently cut by BPS planes (Fig. 2). In synthetic reverse faults or thrusts that dip up the slope, the overall horizontal marker offset (heave) is equivalent to the reverse fault heave $(\mathrm{H})$ and BPS offset combined (Fig. 2a). This results in greater apparent repetition and contraction of marker beds manifested 
by 'staircase' profiles (Fig. 2b, c, d). The heave of marker layers is significantly increased, whilst throw remains largely unaffected (Fig. 2e). In antithetic (downslope-dipping) 'backthrust' faults, the overall horizontal marker offset (heave) is equivalent to the backthrust heave $(\mathrm{H})$ minus the BPS offset and is marked by sawtooth profiles (Fig. 2f). BPS offset greater than backthrust heave results in missing section and negative heave i.e. backthrust faults have extensional offsets due to the effects of later BPS (Fig. 2gj). When multiple BPS planes cut an earlier fault, then the offset of some marker beds may be affected by more than one BPS plane (Fig. 2j). This results in sawtooth profiles with more extreme heave of some beds where the offsets of both BPS 1 and BPS 2 are combined (Fig. 2j). Throw remains largely unaffected by additional BPS planes, although slight increases can be attributed to steeper dips of the early fault (Fig. $2 \mathrm{j}$ ). Having established this geometric framework for the identification and analysis of BPS cutting various types of earlier faults, we now apply these scenarios to our case study area in the Dead Sea Basin.

\section{3) Geologic setting}

\section{1) Regional geology}

The Dead Sea Basin is a pull-apart structure on the Dead Sea Fault (transform), which is marked by two major, left-stepping, sinistral fault strands that generate numerous earthquakes (Fig. 3a, b) (e.g. Marco et al. 1996, 2003; Ken-Tor et al. 2001; Migowski et al. 2004; Begin et al. 2005; Levi et al., 2006a, b). This transform is thought to have been active from the early Miocene to recent, (Nuriel et al., 2017) including during deposition of the Lisan Formation in the Late Pleistocene (70-14 Ka) (e.g. Bartov et al. 1980; Garfunkel 1981; Haase-Schramm et al. 2004). The Lisan Formation, that forms the present case study, comprises mm-scale aragonite laminae that were precipitated from hypersaline waters of Lake Lisan during the summer, together with more detrital-rich layers washed into the lake during flood events (Begin et al. 1974; Dor et al. 2019). Counting of the aragonite-detrital varves, when combined with isotopic dating, suggests that the Lisan Formation was deposited at an average rate of $\sim 1 \mathrm{~mm}$ per year (Prasad et al., 2009). The detrital units of the Lisan Formation consist of quartz and calcite grains with minor feldspar, and clays (illite-smectite) (Haliva-Cohen et al., 2012). Detrital laminae display grain sizes of $\sim 8$ $10 \mu \mathrm{m}$ (silt), while the thicker $(>10 \mathrm{~cm})$ detrital-rich units are very fine $(60-70 \mu \mathrm{m})$ sands (HalivaCohen et al., 2012). Although deposited on slopes of $<1^{\circ}$, the Lisan Formation contains numerous MTDs that are capped by undeformed beds and are considered to be seismically triggered by earthquakes along the bounding fault system (Marco et al., 1996; Agnon et al., 2006; Alsop et al., 2016; Lu et al., 2017; Levi et al., 2018).

\section{2) Regional MTD patterns}

The Lisan Formation is exposed for $\sim 100 \mathrm{~km}$ along the western margin of the Dead Sea Basin and contains MTDs with fold and thrust systems that define an overall radial pattern of slumping directed towards the depo-centre of the basin (Alsop et al. 2016; 2020) (Fig. 3a, b). MTDs move towards the ESE in the northern portions of the basin, in the central part around Miflat and Masada the MTDs are directed towards the east, whilst in the southern area around Peratzim MTDs are NE-directed (Alsop et al. 2016) (Fig. 3b). Combined with westerly-directed slumping recorded from the eastern shore of the Dead Sea in Jordan (El-Isa \& Mustafa 1986), this confirms a radial pattern of MTD movement towards the depocentre of the Dead Sea Basin (Alsop et al. 2016). The combined input of MTDs from around the margins of the basin leads to increased sediment accumulation in the depo-centre, with drill cores from the centre 
revealing numerous MTDs and the stratigraphic thickness of the Lisan Formation being three times greater than its currently exposed onshore equivalent (Lu et al., 2017; Kagan et al., 2018). In the extreme southern area, MTDs are directed towards the south and are interpreted to be influenced by the nearby NE-SW trending Amazyahu Fault (Weinberger et al. 2017, Alsop et al. 2018a; 2020) (Fig. 3b). This overall pattern of radial MTD movement has been subsequently corroborated by analysis of Anisotropy of Magnetic Susceptibility (AMS) fabrics (Weinberger et al. 2017).

The Dead Sea Basin is an ideal place to study structures associated with MTDs as it is well exposed at outcrop with the intricate varve-like stratigraphy defining a range of detailed structures (Fig. 1b $\mathrm{g}, 2 \mathrm{~b}, \mathrm{~g})$. The present study focusses on MTD horizons and BPS planes that are best exposed in outcrops

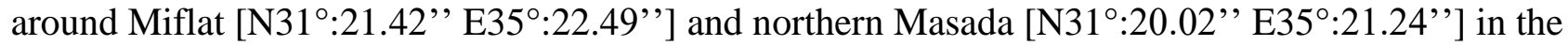
central Dead Sea area (Fig. 3b-e) (see Weinberger et al. 2017). This study area is positioned $\sim 1 \mathrm{~km}$ east of the Dead Sea western border fault zone, with Cenomanian-Senonian carbonates preserved further to the west in the footwall to this fault (Fig. 3b, c, d). For most of the time between 70 and $28 \mathrm{Ka}$, Lake Lisan in this area had a maximum depth of $100 \mathrm{~m}$ or less, apart from a brief period from 26-24 Ka when water was up to 200 m deep (Bartov et al. 2002; 2003).

\section{3) MTD and BPS displacement directions}

MTDs within the Lisan Formation are defined by deformed units up to $3 \mathrm{~m}$ thick that are bound above and below by undeformed beds. Overlying beds locally erode the underlying fold and thrust systems, indicating that MTDs originally formed at the sediment surface (e.g. Alsop and Marco, 2012; Alsop et al., 2016; 2019a). In a number of cases, the MTDs are overlain by undeformed gypsum-rich beds that formed after the slope failure and define prominent benches in cliff sections (Fig. 4a). These competent gypsum beds generally remain unaffected by MTDs, but occasionally we note that they are deformed by a series of detachment folds (Fig. 4b-d). Detachment folds are defined by McClay (1992 p.428) as 'folds developed above a detachment or thrust that is bedding parallel' and form where beds above the detachment shorten more than those beneath it that commonly remain undeformed (e.g. Fossen, 2016, p.367). The detachment folds develop above BPS planes and therefore provide a further indication of the direction of BPS towards the ENE $\left(080^{\circ}\right)$ (Fig. 3i). Detachment folds display classic buckle fold geometries that verge downslope towards the east, and may intensify into recumbent folds cut by local thrusts (Fig. 4b, c, d). Limits of continuous exposure typically restrict the tracing of individual BPS planes to $<50 \mathrm{~m}$ (and generally $<20 \mathrm{~m}$ ), while the exact number of early faults that BPS planes cut is dependent on earlier fault density, but numbers are generally $<10$.

The consistency of movement directions from assumed transport-normal fold hinges and axial planes within MTDs $\left(071^{\circ}\right)$ (Fig. 3f), normals to intersections of post-MTD conjugate reverse faults $\left(071^{\circ}\right)$ (Fig. 3g), normals to post-MTD conjugate normal faults $\left(083^{\circ}\right)$ (Fig. 3h) and post-MTD detachment folds and axial planes $\left(080^{\circ}\right)$ (Fig. 3i) allows us to confidently assign a top-to-the ENE (mean $076^{\circ}$ ) direction of movement during slope failure. This is in agreement with the previously determined MTD transport directions determined from the Lisan Formation around the Dead Sea from both fieldbased structural analysis (Alsop et al., 2016; 2020) and corroborated by magnetic fabrics in AMS studies (Weinberger et al. 2017). 


\section{4) Detailed geometry of BPS cutting synthetic (downslope-dipping) normal faults}

In order to establish true geometries and displacements across the BPS planes, we now examine the details of BPS in sections parallel to the downslope transport direction (see section 3.3) above). We provide some examples of downslope-dipping normal faults being cut and displaced by later BPS surfaces. Normal faults displace MTD horizons, indicating that they locally post-date slumping, but are themselves cut by BPS planes (Fig. 4e, f). In detail, earlier faults may be folded as they are cut by BPS planes with local pockets of' 'mixed' gouge being developed (Fig. 4g, h). The BPS planes typically form within weaker aragonite-rich beds, especially where these are overlain by detrital-rich beds (Fig. 4e-h).

In some cases, BPS displays a considerably larger offset, up to one order of magnitude greater, than recorded across the earlier normal fault (Fig. 5a-c). The earlier fault dips towards $079^{\circ}$, the presumed transport-direction and is truncated by the later BPS 1 and BPS 2 planes, with both the fault and the BPS planes being cut by a clastic dyke (Fig. 5a, b). Earlier downslope-verging folds cause a local thickening of MTD stratigraphy that results in a small topographic 'high' and results in thinning of overlying beds (Fig. $5 a, b)$. This indicates that the MTD formed at the sediment surface. Later faults that cut this horizon can be traced up though stratigraphy for several metres and therefore formed below the immediate sediment surface. The two BPS planes cut the earlier normal fault and cause a significant -ve jump in heave due to BPS 2 offset being considerably greater than the earlier normal fault heave (Figs. 1e, 5c, d). Simple 'cut \& paste' restoration of the two BPS planes (Fig. 5e) reveals a moderately ENE-dipping normal fault with an almost constant throw profile (Fig. 5c) supporting the correlation of the fault segments across BPS 2 . Detailed photographs and line drawings of footwall cut-offs (Fig. 5f, g) and hangingwall cut-offs (Fig. 5h, i) beneath and above the transecting BPS 2 surface show extremely sharp truncations of the earlier normal fault with little or no deformation along the glide plane marking BPS.

Individual downslope-dipping normal faults may be cut by several BPS planes to create a 'sawtooth' profile (Fig. 1e, 6a, b). Simple 'cut \& paste' restoration of the three BPS planes (Fig. 6c) reveals a moderately ENE-dipping $\left(082^{\circ}\right)$ normal fault with a throw profile that gradually reduces up the restored fault (Fig. 6d) thereby supporting the correlation of the fault segments across the BPS surfaces. Restoration also shows that the BPS 1 and BPS 2 planes are developed at the same stratigraphic level that is repeated in the footwall and hangingwall of the original normal fault (Fig. 6c, d). This indicates that weak horizons susceptible to BPS may be utilised and re-used several times across early faults. We focus on the middle BPS plane (BPS 2) and show that early normal faults may branch, with some (blue) marker beds being preserved as small units between anastomosing faults above and below BPS 2 (Fig. 6c-g). Normal faults display a slight curving and bending into the later BPS 2 plane, suggesting that the orientation of the original normal fault may have been locally influenced by weak horizons that subsequently became the locus for BPS (Fig. 6e, f, g). Detailed photographs show the early normal fault to be abruptly truncated by the BPS 2 plane that is accompanied by a thin seam of gouge (Fig. $6 \mathrm{~h}, \mathrm{i}$ ). The multiple BPS planes segment the measured heaves across the early normal fault, while the throw remains fairly constant and only slightly decreases upwards along the fault (Fig. 6d). These relationships provide confirmation that the various segments of normal fault have been correctly correlated across the three BPS planes. The apparently -ve offsets across the lower BPS 1 and BPS 2 planes indicates that BPS movement is greater than the original normal fault heave and that stratigraphic sections are being repeated across BPS 1 and BPS 2 (see Fig. 1e for details of process). The upper BPS 3 plane has not fully compensated the earlier normal fault heave and the overall offset therefore remains +ve (Fig. 6d). We observe that the amount of BPS offset reduces across each BPS plane up through the sequence (Fig. 6d). 


\section{5) Detailed geometry of BPS cutting antithetic (upslope-dipping) normal faults}

Normal faults that display opposing (antithetic) sense of movement to later BPS tend to display overall 'staircase' profiles with steeper normal faults cut by flat BPS planes (Figs. 1f, g, 7a-i). The steeper the normal fault, the more distinct the 'step' associated with the cross-cutting BPS plane (Figs. 1f, g, h, 7a, b). Antithetic normal faults dip moderately $\left(50-70^{\circ}\right)$ towards the west, with the opposing azimuth to the dip direction of these faults (Fig. 7e), or the normal to the intersection of conjugate faults (Fig. 7c), suggesting an overall movement direction towards the east or NE (stereonets on Figs. 7c, e). The geometric effect of BPS on antithetic normal faults is for the heave to be increased where they are cut by BPS (Fig. 1f, j, 7d). Local secondary thrusts may develop above the BPS plane and in the hangingwall of the early normal fault (Fig. 7b, c). Such contractional structures may be a consequence of downslope movement along the BPS plane which is partially impeded by detrital-rich beds in the footwall to the normal fault (Fig. 7c). Care should be exercised where antithetic normal faults have curved into a pre-existing weak layer that later became the BPS plane (Fig. 7a, b, c). Although the antithetic fault may superficially resemble a 'ramp-flat' geometry, the displacement along the BPS will not necessarily match the displacement along the early fault. The component of throw remains relatively constant as BPS does not affect this (Fig. 7d). This provides a useful check to distinguish original ramp-flat fault geometries (where throw will diminish into the flat) from later cross-cutting BPS planes.

The effect of BPS planes is compounded where marker beds offset by the early antithetic fault are cut by more than one intervening BPS plane (Fig. 7e, f). The amount of heave experienced by the marker beds therefore depends on if they are simply offset by the normal fault alone, or an additional BPS plane, or more than one additional BPS plane (Fig. 7e-i). For example on Fig. 7e, f, g, the brown marker beds displaced only by the early normal fault display $300 \mathrm{~mm}$ heave, the orange marker bed is affected by the addition of BPS 1 resulting in a heave of $436 \mathrm{~mm}$, and the blue marker bed is offset by both BPS 1 and BPS 2 combined resulting in a heave of $664 \mathrm{~mm}$ (Fig. 7e, f, g). Where multiple BPS planes cut normal faults, the component of throw remains constant, or displays a systematic and steady reduction (in accordance with a reduction in heave where unaffected by BPS) as might be expected along a simple normal fault (Fig. 7f). 'Cut \& paste' restoration of multiple BPS planes may lead to some apparent 'gaps' that are a consequence of the BPS planes being slightly curving and/or irregularities along the outcrop surface (Fig. 7g). Restoration does however indicate that offset generally decreases across each BPS plane up through the sequence (Fig. 7f, g, h, i). Detailed photographs and line drawings (Fig. 7h, i) show that some sedimentary injections are developed along BPS surfaces that may also generate localised secondary thrusts that ramp off the BPS plane (Fig. 7 h, i).

Where two or more marker faults are cut by a later BPS plane, they can provide a useful check on the position and amount of offset across the BPS plane. This assumes that the earlier faults are broadly parallel to one another thereby removing doubts about how the orientation of earlier markers may influence apparent displacements. Given that the orientation of earlier faults may vary slightly, and that displacement may also vary along the BPS surface, restoration of multiple earlier markers should be viewed with caution. It is however found in a number of cases that multiple antithetic earlier faults do indeed restore given the same amount of displacement across the BPS surface (e.g. Fig. 8a-c). In other cases however, multiple antithetic faults do not simply restore (Fig. 8d-f). This suggests either a component of obliquity between early faults, or potential variation in BPS movement direction relative to the outcrop surface. Without direct measurement of movement indicators such as slickenlines which are seldom observed in the soft Lisan sediments, it is impossible to resolve these various scenarios. 


\section{6) Detailed geometry of BPS cutting synthetic (upslope-dipping) reverse faults}

BPS planes may cut earlier synthetic and antithetic reverse faults resulting in the range of previously described geometric scenarios (Fig. 2a-j). We here describe some examples of these relationships and provide further details of the patterns. Synthetic reverse faults generally dip towards the west, with the opposing azimuth to the dip direction indicating the transport direction of $089^{\circ}$ in Fig. 9 a,b,c. Simple 'cut $\&$ paste' restoration of the two BPS planes (Fig. 9c) reveals a moderately west-dipping reverse fault, that locally branches where it cuts horizons that subsequently became the locus of BPS. The lower BPS 1 plane displays the larger offset, with secondary backthrusts that ramp off this being cut by the overlying BPS 2 surface (Fig. 9c). This suggests that the upper BPS 2 plane with smaller (54 mm) displacement is slightly younger than the BPS 1 surface (Fig. 9a, b, c), with both reverse faults broadly restoring across the BPS 2 plane. The lower BPS 1 surface also cuts very gently down through stratigraphy in the transport direction, such that some (purple) marker beds that are transected in the footwall of the BPS 1 plane reappear in the hangingwall further east (Fig. 9a-e). Cut \& paste restoration of the reverse faults across the lower BPS plane also leads to a correlation of this purple marker bed and demonstrates that BPS 1 gently cuts bedding in an extensional sense next to the contractional reverse faults (Fig. 9c). Synthetic reverse faults display a stepped 'staircase' pattern where cut by BPS planes, with BPS offset being potentially larger than the heave of the reverse fault (Fig. 9c, f). The throw of the reverse fault increases slightly at the level of the BPS planes, suggesting that the original reverse fault had a larger displacement at the stratigraphic level that subsequently focussed BPS (Fig. 9f). This is mirrored by a slight increase in reverse fault heave in marker beds above BPS 2. BPS 1 and BPS 2 are both developed beneath the same competent (orange) marker bed in the footwall and hangingwall of the reverse fault respectively (Fig. 9e).

In some instances, the BPS plane cuts both the synthetic reverse fault and the tilted backlimb above the ramp leading to both footwall and hangingwall cut-offs across the BPS plane (Fig. 10a-d). These ramp cut-offs lead to local younger over older stratigraphic relationships across the BPS plane, that revert to older over younger where BPS cuts the reverse fault (Fig. 10a-d). The reduction in reverse fault heave directly beneath the BPS plane is correlated with increasing throw in the same interval and is considered a geometric consequence of increasing reverse fault dip (Fig. 10e). The increased offset in marker beds affected by both reverse synthetic faulting and BPS is a consequence of combining fault heave and BPS (Fig. 2a-e, 10e).

\section{7) Detailed geometry of BPS cutting antithetic (downslope-dipping) reverse faults}

Antithetic reverse faults (or 'backthrusts') dip towards the east and may be cut by single (e.g. Fig. 9g-i, 10a, b) or multiple (e.g. Fig. 2g-i, 10f-g) BPS planes. Multiple BPS planes cutting antithetic reverse faults leads to 'sawtooth' patterns which are marked by missing section across the BPS plane (Fig. 2f-i, 10f, g). As BPS and backthrusts have an opposing antithetic sense of hangingwall movement, the overall heave of offset markers is reduced and may become negative where BPS > fault heave (Fig. 2f-j, 10f-h). In some instances of multiple BPS, the upper BPS 2 plane in the hangingwall of the antithetic reverse fault is at the same stratigraphic level as lower BPS 1 in the footwall of the reverse fault (Fig. 10e,f), while in other cases the BPS is seen to branch and rejoin the same stratigraphic level on either side of an early fault (Fig. 10a. b). These relationships demonstrate the long-lived mechanical control that bedding has on the positioning of BPS in multi-layer sequences. Where thick competent detrital beds are developed above the BPS plane and in the footwall of the backthrust, they may act as a 'bulldozer' and result in minor contractional thrusts in the downslope direction (Fig, 9g-i). 


\section{8) Discussion}

\section{7}

\section{1) Mechanisms that potentially drive BPS}

The range of possible mechanisms that may potentially drive BPS was recently summarised by Delogkos et al. (2018) and are now briefly discussed in relation to BPS within the Lisan Formation. Although flexural slip is widely invoked as a mechanism to create BPS across a range of scales, it can be discounted in the study area as no large-scale folds are observed, with bedding dips remaining constant $\left(<1^{\circ}\right.$ towards the east) all over the study area. Moreover, no flexural slip has been recorded around small-scale folds elsewhere in the Lisan Formation (Alsop et al. 2019b). Similarly, BPS associated with flexural shear created by 'roll-over' next to master faults (e.g. Higgs et al., 1991) can also be discounted as there is no evidence of bedding 'rollover' next to the Dead Sea western border fault zone. In an alternative model, normal faults and BPS are considered to have been active simultaneously during rotation of large blocks above an extensional detachment system (Ferrill et al., 1998). This differs from the case study in that there is no evidence for block rotations within the Lisan Formation, and normal faults and BPS were typically active sequentially rather than simultaneously. We now discuss in more detail a further two mechanisms that could potentially drive BPS in the case study area.

\subsubsection{BPS created by co-seismic shaking}

An alternative mechanism of creating BPS is seismic shaking that generates horizontal slip parallel to bedding (Weinberger et al. 2016). Such co-seismic shaking has been invoked in the Lisan Formation at Peratzim [N31 ${ }^{\circ} 0449.6$ E35 $\left.5^{\circ} 104.2\right]$ (Fig. 3b), where displaced clastic dykes record horizontal BPS on the scale of metres (Weinberger et al. 2016). The co-seismic shaking mechanism creates structures that differ from those recorded in this case study in that: 1) Significant amounts of gouge, that typically range between 2-10 mm thick, are developed along seismically created BPS which are largely absent in the present study. 2) Clastic dykes are displaced concurrently by 5-9 BPS planes stacked one on top of the other, and record displacement profiles typified to horizontal seismic shaking. In the present study, the clastic dykes cut across and post-date faults and BPS planes (e.g. Figs. 5a, b, 6a, b). Moreover, the general settings differ in that BPS associated with seismic shaking is recorded above the Sedom salt Formation and is bound to the east by the Sedom salt wall (e.g. Weinberger et al., 2006; Alsop et al., 2018b). Such a setting may amplify seismicity (Jacoby et al., 2015 ) compared to the Miflat case study area, which has the deepest part of the basin to the east and is therefore unconstrained. Hence, it is unlikely that the BPS structures record co-seismic horizontal slip in the case study, although seismicity may have acted as an initial trigger for BPS movement.

\subsubsection{BPS created by gravity-driven downslope movement}

Gamboa and Alves (2015, p.27) report BPS cutting and displacing metre to decametre scale faults within large individual blocks carried in Tortonian aged MTD's in Crete. These 'fracture meshes' are only recorded within MTD blocks rather than the host sediment, and are interpreted to form during downslope movement which resulted in limited flexuring and flexural slip within the blocks. Sediments underlying these blocks are highly sheared, with intense sheath folding and small-scale sediment injection. Our case study differs in that BPS pervades the host sediment (rather than being restricted to blocks) and does not result from a flexural slip mechanism within the blocks. 
In a series of experiments, Lacoste et al. (2012) have examined the effect of pre-existing downslope incision into mechanically weak layers on gravity-driven mass movements. They find that a 'free surface' associated with a lack of supporting downslope sediments, combined with increased fluid over-pressures, results in an increase in the length of the sliding sheet. They also note that "the lack of a downslope buttress critically reduces the forces resisting sliding and trigger deformation" (Lacoste et al. 2012, p.159). In the case study, the slope gradients and water depth increase towards the deepest part of the basin which is located further to the east (Fig. 3b, c, d). This would encourage slope failure, with slumps associated with MTDs in the deep basin considered to be sourced from this slope area (Lu et al., 2017). Removal of sediment from the slope via MTDs that flow directly into the deep basin may encourage further gravity-driven movement of the basin margin sediments that form the present study

To summarise, 1) BPS is associated with a general top to-the east movement in every recorded case ; 2) BPS slip direction corresponds with earlier MTD and normal/reverse fault movement directions; and 3) BPS appears to be best developed in the northern area where the Dead Sea Basin is at its deepest. Collectively, these observations lead us to conclude that BPS is gravity-driven and results in downslope movement in the same way as earlier MTDs. This broadly equates to 'gravity-gliding' which is developed in tilted beds and according to Stewart and Argent (2000, p. 695) is driven by 'the body weight of a layer sliding upon a relatively weak layer, or 'detachment'.

\section{2) Depth and timing of BPS}

High-quality drill cores with $100 \%$ recovery penetrate to depths of nearly $100 \mathrm{~m}$ in gravitationally deformed shales and sandstones in onshore Japan (Chigira et al., 2013). Within this sequence, minor shear and slip surfaces form sub-parallel to sub-horizontal bedding at depths of up to $85.9 \mathrm{~m}$ (Chigira et al., 2013, p.107). Seismic studies from offshore Korea indicate $60-90 \mathrm{~m}$ thick deposits affected by downslope movement on $<1^{\circ}$ slopes (Lee and Chough, 2001), while $40-50 \mathrm{~m}$ thick sediments undergo slip on $1-4^{\circ}$ slopes from the Beaufort Sea offshore Canada (Hill et al., 1982). Similar $20-30 \mathrm{~m}$ thicknesses of sediment also undergo downslope movement on much lower angle $0.5^{\circ}$ slopes in fjords on Baffin Island (Syvitski, et al., 1987).

Within the case study, the question arises as to whether BPS is truly surficial and is generated within a metre or so of the surface similar to MTDs within the Lisan Formation, or alternatively forms in the shallow sub-surface in a sequence that has been buried to some extent as in the examples quoted above. BPS clearly cuts and post-dates normal and reverse faults that displace MTD and gypsum horizons, indicating that BPS is not entirely surficial. The minimum depth that BPS operated at is equivalent to the maximum distance 'marker' faults can be traced above the BPS planes, which is about $2.5 \mathrm{~m}$ before faults terminate or outcrop is lost. The maximum depth of BPS within the Lisan Formation is equivalent to the thickness of the overlying upper 'white' Lisan sequence which is approximately 20m (Bartov et al., 2002). Sedimentary 'caps' that are deposited out of suspension following rapid slope failure associated with MTDs (e.g. Alsop and Marco, 2012; Alsop et al., 2017a, b) are absent from above BPS planes, potentially also reflecting the sub-surface nature of the BPS deformation. It appears therefore that BPS within the Lisan Formation operated in the shallow sub-surface at metres to $<20 \mathrm{~m}$ depth. It is possible that seismicity that created MTDs at the surface may have encouraged discrete BPS planes to form at slightly greater depths in more consolidated sediment and associated with locally higher pore fluid pressures (see section 8.3 below). 
While the depositional age of the Lisan Formation and its associated MTDs, ranges between 70 and $14 \mathrm{Ka}$ (Kaufman, 1971; Haase-Schramm et al., 2004), the stratigraphic position of the BPS planes in the upper Lisan section (i.e. the 'white cliff' section, Bartov et al., 2002) suggests that the BPS planes formed after $\sim 30 \mathrm{Ka}$. Based on optically stimulated luminescence (OSL) dating, the clasticdyke material that cross-cuts BPS planes ranges in age between 15 and $7 \mathrm{Ka}$, (Porat et al., 2007). These dates bracket a potential age range for BPS, which must be older than $7 \mathrm{Ka}$ (youngest age of clastic dykes) and younger than $30 \mathrm{Ka}$ (depositional age of the 'white cliff' section of the Lisan Formation). Clastic dykes that cut MTDs in the Lisan Formation (e.g. Porat et al. 2007; Levi et al. 2008), suggest that it was fluid-saturated at the time of BPS, with the present fluid content still estimated at $~ 25 \%$ (Arkin and Michaeli, 1986; Frydman et al., 2008). These general ages indicate that BPS developed shortly after the deposition of the Lisan Formation and is not a process linked to 'modern' seismicity, ongoing collapse of wadi walls (that would lead to vatiable slip directions towards the eroded canyons) or the continued drop of lake levels in the Dead Sea Basin.

\section{3) Factors controlling the position and propagation of BPS}

\subsection{1) Position of BPS planes}

Detrital-rich beds within the Lisan Formation have been shown previously to influence the position of detachments, which frequently form directly beneath such competent units that potentially trap underlying fluids (Alsop et al. 2018a). The BPS planes themselves typically develop within weaker aragonite-rich beds (Fig. 4e-h, 6e-h, 7a-d). Normal faults branch into strands (and then rejoin) when passing through competent layers that were then used to focus BPS. For example, synthetic normal faults become multistranded adjacent to competent layers (e.g. Fig. 6a, b). Similar patterns are also observed where reverse faults cut competent layers associated with BPS planes (e.g. Fig. 9d, e). Faults cutting mechanically stronger layers develop more fractures and wider damage zones (Fossen 2016, p. 162) and indicate that mechanical controls on the location of BPS planes also controlled the earlier normal and reverse faults.

The presence and influence of fluids during BPS is shown by the development of sedimentary injections that form along some BPS planes (e.g. Fig. 7h). A 'mosaic' of high-fluid pressure cells may encourage focussing and movement along the BPS plane in a similar way to sub-glacial deformation that is partially controlled by varying fluid pressures (e.g. Lesemann et al. 2010). BPS cutting and displacing early faults may therefore affect the flow of fluids moving along and up these steep faults and thereby influence ongoing deformation during BPS. The observation that clastic dykes cut both the BPS planes and earlier steep faults indicates that some over-pressured units were present and remained after BPS.

Other mechanically controlling units include gypsum-rich beds that may also trap underlying fluids (e.g. Fig. 10a-d). Detachment folds of gypsum beds develop above BPS planes that also cut across earlier thrusts and reverse faults (Fig. 4b, c, d, 10a-d). We stress that volume changes associated with the anhydrite-gypsum transition are not considered the cause of the detachment folds in gypsum that we describe here as i) detachment folds are broadly coaxial with folds developed in adjacent gravity-driven MTDs (Fig. 3f, i); ii) detachment folds display a pronounced downslope vergence that culminates in eastverging thrusts (Fig. 4b, c, d); iii) gypsum layers observed elsewhere in the Lisan Formation do not display detachment folds with pronounced downslope vergence. These observations collectively suggest that downslope translation above BPS planes is the cause of the detachment folding, rather than any volume changes associated with the anhydrite to gypsum transition. In summary, mechanical stratigraphy 
appears to be important in focussing BPS along certain horizons, with detrital- rich beds acting as competent units that trap underlying fluids and encourage BPS.

\subsection{2) Propagation of BPS planes}

Although the direction of BPS in the case study is always with a top-to-the-east sense of movement, the direction of failure propagation along the BPS surface may be either upslope or downslope directed (see Farrell, 1984). The direction of BPS propagation may be ascertained by examining mechanical controls on BPS levels on either side of early faults. If strong mechanical controls exist on one margin of an early fault then that may provide an indication that the BPS movement initiated on that side of the fault. As noted previously, the stratigraphic level of BPS planes vary where they cross earlier faults. If the level of BPS planes is partially controlled by mechanical stratigraphy, with detrital-rich beds typically being more competent and potentially trapping underlying fluids (see above and Alsop et al. 2018a, 2019b), then the location of the 'controlling' bed in the footwall or hangingwall of the normal fault provides an indication of the direction from which the BPS propagated. Where a BPS plane passes from a strong mechanical control (aragonite overlain by detrital) to no apparent control as it cuts an earlier fault, it is likely that the BPS plane originated in the area of marked control, rather than fortuitously propagating into such a setting. Clearly, these observations are best where there is distinct differences in stratigraphy across the earlier fault.

\subsubsection{Re-use of BPS planes}

BPS planes are re-used where the same stratigraphic horizon is utilised by BPS in both the footwall and hangingwall of an earlier normal fault (e.g. Figs. 6a-c, 11a-d), reverse fault (e.g. Figs. 9a-e, 11e, f) or backthrust (e.g. Figs. 10a, b, 11g, h). This results in two BPS planes that are at the same stratigraphic position in the hangingwall and footwall of the earlier fault, but subsequently propagate across the earlier fault. In this case, one of the BPS planes must have initiated downslope and one upslope of the earlier fault, otherwise they would not 'pick' the same competent horizon (Fig. 11a-h). Ferrill et al. (1998 p.360) note that for BPS to be transferred and cut across earlier faults, 'relatively weak layers (those poised for slip or shear) must align across faults with similarly poised layers'. This general point on mechanical layering may indeed be relevant to BPS in the Lisan Formation. The re-use of weak horizons results in multiple BPS planes with associated sawtooth and staircase profiles, and highlights the mechanical control and inheritance of weak BPS planes (Fig. 11a-h). These observations collectively suggest that while there is a consistent top-to-the-east sense of BPS movement, there is no systematic pattern of BPS propagation either up or down the regional slope (Fig. 11a-h).

\section{4) Geometric consequences of BPS in gravity-driven systems}

\subsubsection{BPS affecting heave across early faults}

Collectively, BPS planes may significantly influence the heave of extensional normal faults and contractional reverse faults across a MTD system (Figs. 1,2). Although the amount of BPS offset may be similar, the effects on heave by creating 'staircase' geometries in upslope dipping faults, or by telescoping downslope dipping faults, are quite different (Fig. 11a-h). 
i) In upslope-dipping normal and reverse faults, the BPS heave is simply combined with early fault heave to create a significant increase in overall heave across the fault zone (Fig. 1f, 2a, 11c-f ).

ii) Alternatively, in downslope dipping normal and reverse faults, BPS must first compensate and remove the effects of early fault heave meaning that overall heave will not be increased by the same amount (Fig. 1a, 2f, 11a, b, g, h).

iii) In all of these four cases described above (Fig. 11), the throw of the early faults are not affected by the later BPS planes.

\subsubsection{BPS affecting stratigraphic patterns across early faults}

This study has recognised that there are four possible overprinting scenarios for BPS intersecting an early fault between the footwall and hangingwall cut-offs of a chosen stratigraphic marker layer. We summarise and highlight these key geometric and stratigraphic relationships below and in Fig. 12.

i) Later BPS and an earlier normal fault have the same (synthetic) sense of hangingwall movement resulting in 'sawtooth' profiles with repeated sections marked by older over younger stratigraphic relationships that are telescoped across the BPS plane (Fig. 12a);

ii) Later BPS and an earlier normal fault have an opposing (antithetic) sense of hangingwall movement, resulting in 'staircase' profiles with missing sections marked by younger over older stratigraphic relationships that are extended across the BPS plane (Fig. 12b);

iii) Later BPS and an earlier reverse fault have the same (synthetic) sense of hangingwall movement, resulting in 'staircase' profiles with repeated sections marked by older over younger stratigraphic relationships that are extended across the BPS plane (Fig. 12c) and

iv) Later BPS and an earlier reverse fault have an opposing (antithetic) sense of hangingwall movement, resulting in 'sawtooth' profiles with missing sections marked by younger over older stratigraphic relationships that are telescoped across the BPS plane (Fig. 12d).

This general framework leads us to some key interpretations. As a single BPS plane may cut several earlier faults, it is possible for the BPS plane to intersect different stratigraphic levels where it crosses the earlier fault. Hence, BPS planes will not always be developed at the same stratigraphic level as their position will also be dependent on the vertical offset of the earlier fault(s). In addition, older over younger stratigraphic relationships and repeated sections across the BPS plane are entirely a consequence of normal faulting cut by later BPS (Fig. 12a). There is no necessity for contraction to create these geometries. Conversely, younger over older stratigraphic relationships associated with missing section that are typical of extensional tectonics are a consequence of thrust faulting cut by BPS (Fig. 12d).

Only small-scale BPS displacement is identified in the present case study due to limitations of scale of outcrop, with an inability to correlate markers across large BPS planes. However, a lack of matching fault markers at outcrop suggests that some BPS potentially conceal 10's metres displacement. It should also be stressed that the effects of BPS planes are not dependent on the amount of movement on any one plane, but rather the cumulative effect of numerous minor slip planes that may collectively result in significant BPS offset of earlier marker faults. Although such offsets are below the limits of seismic resolution and largely 'invisible' in most situations, their combined effects may be significant in terms of estimating extension and contraction in gravity-driven systems such as MTDs. 


\section{9) Conclusions}

This work forms the first detailed study that documents, describes and distinguishes the effects of BPS on earlier normal and reverse faults. We establish a geometric framework that incorporates a range of four possible overprinting relationships depending on if the hangingwall of later BPS has moved in the same (synthetic) or opposite (antithetic) sense to the earlier 'marker' faults (Figs. 11, 12). In addition, the final geometries depend on if the pre-existing faults had a normal (Fig. 12a, b) or reverse sense of (hangingwall) movement (Fig. 12c, d). This study allows us to draw the following specific conclusions.

1) Within the Lisan Formation of the case study area, BPS planes form across a range of stratigraphic levels and pervasively cut earlier structures. BPS is not restricted to any particular lithology or location near boundary fault zones, and forms by gravity-driven downslope movement that is parallel to earlier slope failures associated with MTD's. BPS cuts pre-existing faults that may be traced for several metres through the overlying Lisan Formation, suggesting that BPS operated in the shallow sub-surface at $<20 \mathrm{~m}$ depth. Seismicity that triggered MTDs at the surface may have encouraged discrete BPS planes to form at slightly greater depths in more consolidated (and locally over pressured) sediment.

2) The position of BPS planes is controlled by detrital-rich beds that have been shown previously to trap underlying fluids and influence the position of detachments, that form directly beneath such competent units. It is notable that BPS planes frequently develop beneath detrital-rich beds in both the upslope and downslope sides of early faults. Gypsum-rich beds also provide a control with BPS planes forming below such units.

3) The direction of BPS propagation can be determined by examining distinct mechanical controls on one side of an early fault that suggest that BPS initiated on that margin. Where BPS has two surfaces that utilise the same displaced stratigraphic horizon either side of an early fault, then one BPS plane must propagate downslope and the other upslope to cut the earlier fault. Although BPS is always associated with top-to-the east downslope movement, there appears to be no consistent direction of upslope or downslope BPS propagation.

4) In antithetic normal faults and synthetic reverse faults, the total offset of marker horizons separated by downslope-directed BPS is equivalent to fault heave $(\mathrm{H})+$ BPS offset. In synthetic normal faults and antithetic (back) thrust faults, the total offset of marker horizons separated by downslope-directed BPS is equivalent to fault heave $(\mathrm{H})$ - BPS offset. BPS heave may be greater than or less than the heave of the earlier fault it truncates.

5) The net effect of BPS is to increase and 'telescope' the overall dip of the downslope dipping fault 'zones' resulting in 'sawtooth' profiles. Typical stratigraphic relationships are reversed across these BPS planes such that telescoped normal faults are marked by older over younger beds, whereas BPS cutting antithetic backthrusts results in younger over older stratigraphy. Conversely, BPS affecting upslope dipping fault zones results in extended profiles associated with 'staircase' patterns marked by reduced dips and increased heave.

\section{Acknowledgements}


RW was supported by the Israel Science Foundation (ISF grant No. 868/17). SM acknowledges the Israel Science Foundation (ISF grant No. 1436/14) and the Ministry of National Infrastructures, Energy and Water Resources (grant \#214-17-027). TL acknowledges the Israeli government GSI DS project 40706.

\section{Figure Caption}

Figure 1 Schematic diagrams showing the effect of bed-parallel slip (BPS) cutting a-e) an earlier synthetic normal fault, and f-j) an earlier antithetic normal fault. Total marker offset in a) is the fault heave (H) minus the BPS offset (and is denoted -ve where BPS $>\mathrm{H}$ ), whereas in f) total marker offset is the combined fault heave plus the BPS (denoted $+v e$ ). In a) and f), total marker offset combines $1 / 2 \mathrm{H}$ from each margin of the earlier fault. Photographs and associated line drawings of light-coloured aragonite-rich laminae and dark detrital-rich laminae forming the Lisan Formation and showing an example b-c) of a BPS plane cutting an earlier synthetic normal fault, and g-h) an example of a BPS plane cutting an earlier antithetic normal fault. 'Cut \& paste' restoration of the BPS planes are shown in d) and i) e, j) The graphs compare types of marker offset (heave, throw) across the fault planes shown in b) and g) and highlight (in green) where marker beds have subsequently been displaced by BPS (Fig. 1e, 1j). Green triangles highlight the true horizontal displacement of overlying beds that have been passively carried downslope on the underlying BPS plane. Distance along fault is measured upwards from an arbitrary reference point.

Figure 2 Schematic diagrams showing the effect of bed-parallel slip (BPS) cutting a-e) an earlier synthetic reverse fault, and f-j) an earlier antithetic reverse fault. Total marker offset in a) is the combined fault heave (H) plus BPS (denoted +ve), whereas in f) total marker offset is fault heave minus the BPS (and is denoted -ve where BPS $>\mathrm{H}$ ). In a) and $\mathrm{f}$ ), total marker offset combines $1 / 2 \mathrm{H}$ from each margin of the earlier fault. Photographs and associated line drawings of light-coloured aragonite-rich laminae and dark detrital-rich laminae forming the Lisan Formation and showing an examples b-c) of a BPS plane cutting an earlier synthetic reverse fault, and g-h) an example of a BPS plane cutting an earlier antithetic reverse fault. 'Cut \& paste' restoration of the BPS planes are shown in d) and i) e, j) The graphs compare types of marker offset (heave, throw) across the fault planes shown in b) and g) and highlight (in green) where marker beds have subsequently been displaced by BPS (Fig. 2e, 2j). Green triangles highlight the true horizontal displacement of overlying beds that have been passively carried downslope on the underlying BPS plane. Distance along fault is measured upwards from an arbitrary reference point.

Figure 3 a) Tectonic plates in the Middle East. General tectonic map showing the location of the present Dead Sea Fault (DSF) which transfers the opening motion in the Red Sea to the Taurus-Zagros collision zone. Red box marks the study area in the Dead Sea Basin. b) Generalised map (based on Sneh and Weinberger 2014) showing the current Dead Sea including the position of the Miflat locality referred to in the text. The extent of the Lisan Formation outcrops are also shown, together with the general slump directions of the MTD's around the basin. c) Detailed geological map (after Sneh and Rosensaft, 2019) and d) east-west cross section of the Miflat study area. For location of section see A-A' in c). e) Drone photograph from Miflat [N31 ${ }^{\circ}: 21: 41.897$ E35 $\left.: 22: 48.041\right]$ looking southward along the Dead Sea Basin. Note the incised wadis in the Lisan Formation that is overlain by the Holocene alluvial Ze'elim fan emanating from one of the major wadis cutting the Cretaceous margin of the basin. Competent gypsum beds form prominent benches within the Lisan Formation. f) Fold hinges and associated axial planes developed within MTDs. g) Reverse faults that cut earlier MTD horizons, with antithetic backthrusts shown by dashed great circle (and poles as solid red squares). h) Upslope and downslope-dipping normal faults that cut earlier MTD horizons. East dipping faults shown by blue great circle and poles as solid blue circles $(\mathrm{N}=118)$; westdipping faults by dashed great circle and poles as solid blue squares $(\mathrm{N}=50)$. i) Detachment fold hinges (solid green circles) and associated poles to axial planes (solid green squares) developed above BPS planes. In each case, large arrows represent mean transport directions calculated from normals to the fold hinge trend and axial-planar strike.

Figure 4 a) View (mirrored photograph) of Mass Transport Deposit (MTD) folding within the Lisan Formation. Note the general easterly vergence of folds towards the Dead Sea Basin (see Fig. $3 \mathrm{f}$ for associated fold data). The deformed MTD horizon is overlain by undeformed beds and a competent gypsum horizon that caps the cliff in the 
Lisan Formation. b) Easterly-verging detachment fold train that forms above a BPS plane and deforms the overlying gypsum horizon. c-d) shows details of each fold and underlying BPS plane. Note how folding intensifies downslope towards the east, culminating in a recumbent fold that is thrust over the gypsum horizon. Photograph (e) and associated line drawing (f) that show a downslope-dipping normal fault cutting an earlier MTD horizon and associated minor thrust. The normal fault is itself then cut by a BPS plane with top-to-the-east movement. Photograph (g) and associated line drawing (h) showing details of a synthetic normal fault being cut by a BPS plane. Note how the normal fault is locally folded along the BPS plane. $10 \mathrm{~cm}$ chequered rule and $15 \mathrm{~mm}$ diameter coin for scale in photographs.

Figure 5 Photograph (a) and associated line drawing (b) showing a synthetic (downslope-dipping) normal fault being cut by two BPS planes resulting in a sawtooth pattern. In b), the stereonet shows the orientation of normal fault segments with calculated (strike-normal) transport towards $079^{\circ}$. c) Graph comparing types of marker offset (heave, throw) across the fault plane shown in a) and d). The green line indicates the stratigraphic level of the BPS plane in the hangingwall of the normal fault, while the green tone indicates the beds separated by the BPS planes thereby affecting the heave. e) Line drawing and 'cut \& paste' restoration of the synthetic normal fault across the two BPS planes. Detailed close-up photographs and associated line drawings of $\mathrm{f}-\mathrm{g}$ ) normal fault truncation beneath the BPS plane, and h-i) ) normal fault truncation above the BPS plane. The normal fault and BPS plane are cut by a later clastic dyke. $30 \mathrm{~cm}$ long hammer, $10 \mathrm{~cm}$ chequered rule and $15 \mathrm{~mm}$ diameter coin for scale.

Figure 6 Photograph (a) and associated line tracing (b) showing a synthetic (downslope-dipping) normal fault being cut by three BPS planes resulting in a sawtooth pattern. c) Line drawing and 'cut \& paste' restoration of the synthetic normal fault across the three BPS planes. In c), the inset stereonet shows the orientation of the normal fault segments $(\mathrm{N}=2)$ with calculated (strike-normal) transport towards $082^{\circ}$. d) Graph comparing types of marker offset (heave, throw) across the fault plane shown in a) and c). The green line indicates the stratigraphic level of the BPS plane in the hangingwall of the normal fault, while the green tone indicates the beds separated by the three BPS planes thereby affecting the heave. e) Photograph showing displacement of the normal fault across BPS 2, with details of the cut-off above the BPS shown in $\mathrm{f}-\mathrm{g}$ ) and details of the footwall cut-off shown in $\mathrm{h}-\mathrm{i}$ ). $10 \mathrm{~cm}$ chequered rule and $15 \mathrm{~mm}$ diameter coin for scale.

Figure 7 Photograph (a), annotated photograph (b) and associated line drawing (c) of an antithetic (upslopedipping) normal fault being cut by a BPS plane resulting in a stepped 'staircase' pattern. In c), the inset stereonet shows the orientation of the conjugate normal faults $(\mathrm{N}=2)$ with calculated (intersection-normal) transport towards $085^{\circ}$. d) Graph comparing types of marker offset (heave, throw) across the fault plane shown in a) and c). The green line indicates the stratigraphic level of the BPS plane in the hangingwall of the normal fault, while the green tone indicates the beds separated by the BPS plane thereby affecting the heave but not the throw. e) Photograph of an antithetic (upslope-dipping) normal fault being cut by two BPS planes resulting in a stepped 'staircase' pattern. In e), the inset stereonet shows the orientation of the normal fault segments $(\mathrm{N}=2)$ on either side of the BPS planes with calculated (strike-normal) transport towards $055^{\circ}$. f) Graph comparing types of marker offset (heave, throw) across the fault plane shown in e). The green lines indicate the stratigraphic level of the two BPS planes in the hangingwall of the normal fault, while the green tone indicates the beds separated by the two BPS planes thereby affecting the heave. Beds affected by both BPS 1 and BPS 2 display cumulative offset. g) Line drawing and 'cut \& paste' restoration of the antithetic normal fault shown in e) cut by the two BPS planes. The line drawings highlight how the total heave of various marker beds is controlled by offset across one or two BPS planes. h) Photograph and associated line drawing (i) showing details of BPS1 and BPS2 planes, together with localised normal faulting and thrust faulting.

Figure 8 a) Photograph and associated line tracing (b) of two antithetic normal faults being cut by two BPS planes resulting in a 'staircase' pattern. Clastic dyke subsequently cuts both normal faults and BPS planes. c) Line drawing and 'cut \& paste' restoration of the antithetic normal faults cut by the two BPS planes. Both normal faults have been offset by the same BPS heave indicating negligible displacement gradient along the BPS plane. d) Photograph and associated line tracing (e) of two antithetic (upslope-dipping) normal faults being cut by two BPS planes resulting in a 'staircase' pattern. f) Line drawing and 'cut \& paste' restoration of two antithetic normal faults cut across by the 
two BPS planes. Note that normal faults have been offset by different amounts of BPS heave indicating a potential displacement gradient along the BPS plane.

Figure 9 Photograph (a) and annotated photograph (b) showing synthetic upslope-dipping reverse fault being cut by two BPS planes. c) Line drawing and 'cut \& paste' restoration of the reverse fault cut by the two BPS planes. Note how BPS 1 gently transgresses stratigraphy so that the thin purple marker bed is cut-off in its footwall and reappears downslope on the hangingwall to the right. d) Photograph and line drawing (e) showing details of BPS cut-offs. f) Graph comparing types of marker offset (heave, throw) across the reverse fault and BPS planes plane shown in d). The green lines indicate the stratigraphic level of the BPS planes in the hangingwall of the reverse fault, while the green tone indicates the beds separated by the BPS planes. Photograph $(\mathrm{g})$ and annotated photograph $(\mathrm{h})$ showing antithetic downslope-dipping reverse fault being cut by two BPS planes. i) Line drawing and 'cut \& paste' restoration of the reverse fault cut by the two BPS planes. Note how contractional thrusts develop off the BPS plane downslope of the antithetic reverse fault.

Figure 10 Photograph (a) and associated line drawing (b) of synthetic and antithetic reverse faults being cut by BPS plane beneath a gypsum horizon. Stereonet inset in $b$ ) shows orientation of reverse faults that define a conjugate system with the normal to the conjugate intersection suggesting transport towards $068^{\circ}$. c) Photograph and associated line drawing (d) showing detail of synthetic thrust cut by BPS, and placing younger over older stratigraphic relationships on the back limb of the thrust. e) Graph comparing types of marker offset (heave, throw) across the reverse fault and BPS planes plane shown in d). f) Photograph and 'cut and paste' restored line drawing (g) of antithetic reverse fault being cut by multiple BPS planes. Note that BPS 1 in the footwall of the reverse fault is at the same stratigraphic level that BPS 2 attains in the hangingwall. h) Graph showing heave and throw across BPS 1 and BPS 2 shown in f). Heave is stepped across the BPS planes, whereas throw progressively increases up the early fault plane.

Figure 11 Schematic diagrams illustrating multiple bed-parallel slip (BPS) planes located beneath the same competent marker bed, and cutting normal faults with a, b) synthetic and c, d) antithetic senses of displacement. Multiple BPS planes cut reverse faults with e, f) synthetic and $g, h$ ) antithetic senses of displacement. In each case, the structural evolution is shown from stage 1 after early faulting (on left) and stage 2 after BPS (on right). Downslope-dipping normal and thrust faults $(b, h)$ are telescoped by BPS resulting in sawtooth profiles and a reduction in early fault heave, whereas upslope-dipping normal faults and thrust faults form staircase profiles $(\mathrm{d}, \mathrm{f})$ and have their heave increased. In all cases, BPS initiates at the sites marked (2) below the competent marker bed both upslope and downslope of the early fault, and then each BPS plane propagates in opposite directions to displace the early fault (shown by dashed green lines with open arrows).

Figure 12 Schematic diagrams illustrating bed-parallel slip (BPS) cutting normal faults with a) synthetic and b) antithetic senses of displacement. BPS cuts reverse faults with c) synthetic and d) antithetic senses of displacement. In each case, the structural evolution is shown from stage 1 with projected early fault, stage 2 after early faulting and stage 3 after BPS. BPS cutting synthetic early faults (a, c) results in older over younger stratigraphic relationships together with repeated sections across the BPS plane. BPS cutting antithetic early faults (b, d) results in typical younger over older stratigraphic relationships together with missing sections along the BPS plane. In addition, telescoped sawtooth profiles are formed in a) and d), whereas extended staircase profiles are created in b) and c).

\section{References}

766 Agnon, A., Migowski, C., Marco, S., 2006. Intraclast breccia layers in laminated sequences: recorders of paleoearthquakes, in Enzel, Y., Agnon, A., and Stein, M., eds., New Frontiers in Dead Sea Paleoenvironmental Research, Geological Society of America Special Publication, p. 195-214.

769 Alsop, G.I., Marco, S. 2012. Tsunami and seiche-triggered deformation within offshore sediments. Sedimentary 770 Geology 261, 90-107. 
Alsop, G.I., Marco, S., Weinberger, R., Levi, T. 2016. Sedimentary and structural controls on seismogenic slumping within Mass Transport Deposits from the Dead Sea Basin. Sedimentary Geology 344, 71-90.

Alsop, G.I., Marco, S., Levi, T., Weinberger, R. 2017a. Fold and thrust systems in Mass Transport Deposits. Journal of Structural Geology 94, 98-115.

Alsop, G.I., Marco, S., Weinberger, R., Levi, T. 2017b. Upslope-verging back thrusts developed during downslopedirected slumping of mass transport deposits. Journal of Structural Geology 100, 45-61.

Alsop, G.I., Weinberger, R., Marco, S. 2018a. Distinguishing thrust sequences in gravity-driven fold and thrust belts. Journal of Structural Geology 109, 99-119.

Alsop, G.I., Weinberger, R., Marco, S., Levi, T. 2018b. Fault and fracture patterns around a strike-slip influenced salt wall. Journal of Structural Geology 106, 103-124.

Alsop, G.I., Weinberger, R., Marco, S., Levi, T. 2019a. Identifying soft-sediment deformation in rocks. Journal of Structural Geology, 125, 248-255.

Alsop, G.I., Weinberger, R., Marco, S., Levi, T. 2019b. Folding during soft-sediment deformation. Geological Society Special Publication, Bond, C.E. and Lebit, H.D. (Editors) Folding and fracturing of rocks: 50 years since the seminal text book of J.G. Ramsay. 487, 81-104. doi.org/10.1144/SP487.1

Alsop, G.I., Weinberger, R., Marco, S., Levi, T. 2020. Fold and thrust systems in mass transport deposits around the Dead Sea Basin. In: Ogata, K., Festa, A., Pini, G.A. (Editors). Submarine landslides: subaqueous mass transport deposits from outcrops to seismic profiles. American Geophysical Union Monograph Series. Wiley. p.139-154 (in press).

Arkin, Y., Michaeli, L., 1986. The significance of shear strength in the deformation of laminated sediments in the Dead Sea area. Israel Journal of Earth Sciences 35, 61-72.

Armandita, C., Morley, C.K., Rowell, P. 2015. Origin, structural geometry, and the development of a giant slide: The South Makassar Strait mass transport complex. Geosphere, 11, 376-403. doi:10.1130/GES01077.1

Bartov, Y., Steinitz, G., Eyal, M., Eyal, Y., 1980. Sinistral movement along the Gulf of Aqaba - its age and relation to the opening of the Red Sea: Nature 285, 220-221.

Bartov, Y., Stein, M., Enzel, Y., Agnon, A., Reches, Z., 2002. Lake levels and sequence stratigraphy of Lake Lisan, the late Pleistocene precursor of the Dead Sea. Quaternary Research 57, 9-21.

Bartov, Y., Goldstein, S.L., Stein, M., Enzel, Y. 2003. Catastrophic arid episodes in the Eastern Mediterranean linked with the North Atlantic Heinrich events. Geology 31, 439-442.

Begin, Z.B., Ehrlich, A., Nathan, Y., 1974, Lake Lisan, the Pleistocene precursor of the Dead Sea: Geological Survey of Israel Bulletin, 63, p. 30.

Begin, B.Z., Steinberg, D.M., Ichinose, G.A., and Marco, S., 2005. A 40,000 years unchanging of the seismic regime in the Dead Sea rift: Geology, v. 33, p. 257-260.

Chapple, W.M., Spang, J.H. 1974. Significance of layer-parallel slip during folding of layered sedimentary rocks. Geological Society of America Bulletin 85, 1523-1534.

Chigira, M., Hariyama, T., Yamasaki, S. 2013. Development of deep-seated gravitational slope deformation on a shale dip-slope: Observations from high-quality drill cores. Tectonophysics 605, 104-113.

Delogkos, E., Childs, C., Manzocchi, T., Walsh, J.J., Pavlides, S. 2017. The role of bed-parallel slip in the development of complex normal fault zones. Journal of Structural Geology 97, 199-211.kj

Delogkos, E., Childs, C., Manzocchi, T., Walsh, J.J. 2018. The nature and origin of bed-parallel slip in Kardia Mine, Ptolemais Basin, Greece. Journal of Structural Geology 113, 115-133.

de Vera, J., Granado, P., McClay, K. 2010. Structural evolution of the Orange Basin gravity-driven system, offshore Namibia. Marine and Petroleum Geology 27, 223-237. 
814 Dor, Y.B., Neugebauer, I., Enzel, Y., Schwab, M.J., Tjallingii, R., Erel, Y., Brauer, A. 2019. Varves of the Dead Sea

sedimentary record. Quaternary Science Reviews 215, 173-184.

El-Isa, Z.H., Mustafa, H. 1986. Earthquake deformations in the Lisan deposits and seismotectonic implications. Geophysical Journal of the Royal Astronomical Society 86, 413-424.

Farrell, S.G. 1984. A dislocation model applied to slump structures, Ainsa Basin, South Central Pyrenees, Journal of Structural Geology 6, 727-736.

Farrell, S.G., Eaton, S. 1987. Slump strain in the Tertiary of Cyprus and the Spanish Pyrenees. Definition of palaeoslopes and models of soft sediment deformation. In: Deformation of Sediments and Sedimentary Rocks (edited by Jones, M.F. \& Preston, R.M.F.). Special Publication of the Geological Society of London 29, 181-196.

Ferrill, D.A., Morris, A.P., Jones, S.M., Stamatakos, J.A. 1998. Extensional layer-parallel shear and normal faulting. Journal of Structural Geology 20, 355-362.

Fossen, H. 2016. Structural Geology. $2^{\text {nd }}$ Edition. Cambridge University Press, Cambridge, UK, p.510.

Fowler, T.J., Winsor, C.N. 1997. Characteristics and occurrence of bedding-parallel slip surfaces and laminated veins in chevron folds from the Bendigo-Castlemaine goldfields: implications for flexural-slip folding. Journal of Structural Geology 19, 799-815.

Frydman, S., Charrach, J., Goretsky, I. 2008. Geotechnical properties of evaporite soils of the Dead Sea area. Engineering Geology101, 236-244.

Frey Martinez, J., Cartwright, J., Hall, B. 2005. 3D seismic interpretation of slump complexes: examples from the continental margin of Israel. Basin Research 17, 83-108.

Frey-Martinez, J., Cartwright, J., James, D. 2006. Frontally confined versus frontally emergent submarine landslides: A 3D seismic characterisation. Marine and Petroleum Geology23, 585-604.

Gamboa, D., Alves, T.M. 2015. Three-dimensional fault meshes and multi-layer shear in mass-transport blocks: Implications for fluid flow on continental margins. Tectonophysics 647-648, 21-32.

Gamboa, D, Alves, T.M., 2016. Bi-modal deformation styles in confined mass-transport deposits: Examples from a salt minibasin in SE Brazil. Marine Geology 379, 176-193. doi: 10.1016/j.margeo.2016.06.003

Garcia-Tortosa, F.J., Alfaro, P., Gibert, L., Scott, G. 2011. Seismically induced slump on an extremely gentle slope $\left(<1^{\circ}\right)$ of the Pleistocene Tecopa paleolake (California). Geology 39, 1055-1058.

Garfunkel, Z., 1981. Internal structure of the Dead Sea leaky transform (rift) in relation to plate kinematics: Tectonophysics 80, p. 81-108.

Gee, M.J.R., Gawthorpe, R.L., Friedmann, S.J. 2006. Triggering and evolution of a giant submarine landslide, offshore Angola, revealed by 3D seismic stratigraphy and geomorphology. Journal of Sedimentary Research 76, 919.

Gibert, L., Sanz de Galdeano, C., Alfaro, P., Scott, G., Lopez Garrido, A.C. 2005. Seismic-induced slump in Early Pleistocene deltaic deposits of the Baza Basin (SE Spain). Sedimentary Geology 179, 279-294.

Haase-Schramm, A., Goldstein, S.L., Stein, M. 2004. U-Th dating of Lake Lisan aragonite (late Pleistocene Dead Sea) and implications for glacial East Mediterranean climate change. Geochimica et Cosmochimica Acta 68, 9851005.

Haliva-Cohen, A., Stein, M., Goldstein, S.L., Sandler, A., Starinsky, A. 2012. Sources and transport routes of fine detritus material to the Late Quaternary Dead Sea Basin. Quaternary Science Reviews 50, 55-70.

Heim, A. 1878. Untersuchungen über den Mechanismus der Gebirgsbildung im Anschluss an die geologische Monographie der Tödi-Windgällen-Gruppe. Benno Schwabe, Basel.

Higgs, W.G., Williams, G.D., Powell, C.M. 1991. Evidence for flexural shear folding associated with extensional faults. Geological Society of America Bulletin 103, 710-717. 
Hill, P.R., Moran, K.M., Blasco, S.M. 1982. Creep deformation of slope sediments in the Canadian Beaufort Sea. Geo-Marine Letters 2, 163-170.

Jablonska, D., Di Celma, C., Tondi, E., Alsop, G.I. 2018. Internal architecture of mass-transport deposits in basinal carbonates: A case study from southern Italy. Sedimentology 65 (4), 1246-1276.

Jacoby, Y., Weinberger, R., Levi, T., Marco, S. 2015. Clastic dikes in the Dead Sea Basin as indicators to potential hazard. Natural Hazards, 75:1649-1676, doi:10.1007/s11069-014-1392-0.

Jolly, B.A., Lonergan, L., Whittaker, A.C., 2016. Growth history of fault-related folds and interaction with seabed channels in the toe-thrust region of the deep-water Niger delta. Marine and Petroleum Geology 70, 58-76.

Kagan, E.J., Stein, M., Marco, S. 2018. Integrated palaeoseismic chronology of the last glacial Lake Lisan: From lake margin seismites to deep-lake mass transport deposits. Journal of Geophysical Research: Solid Earth 123 (4) 2806-2824.

Kaufman, A. 1971. U-series dating of Dead Sea basin carbonates: Geochimica et Cosmochimica Acta, 35, 12691281, doi: 10.1016/0016- 7037(71)90115-3.

Ken-Tor, R., Agnon, A., Enzel, Y., Marco, S., Negendank, J.F.W., and Stein, M., 2001. High-resolution geological record of historic earthquakes in the Dead Sea basin: J. Geophys. Res., v. 106, p. 2221-2234.

Lacoste, A., Vendeville, B.C., Mourgues, R., Loncke, L., Lebacq, M., 2012. Gravitational instabilities triggered by fluid overpressure and downslope incision-Insights from analytical and analogue modelling. J. Struct. Geol. 42, 151162.

Lee, S.H., Chough, S.K. 2001. High-resolution (2-7 kHz) acoustic and geometric characters of submarine creep deposits in the South Korea Plateau, East Sea. Sedimentology 48, 629-644.

Lesemann, J.E., Alsop, G.I., Piotrowski, J.A. 2010. Incremental subglacial meltwater sediment deposition and deformation associated with repeated ice-bed decoupling: a case study from the Island of Funen, Denmark. Quaternary Science Reviews 29, 3212-3229.

Levi, T., Weinberger, R., Aifa, T., Eyal, Y., S. Marco, S. 2006a. Injection mechanism of clay-rich sediments into dikes during earthquakes, Geochemistry, Geophysics, and Geosystems 7, no. 12, Q12009.

Levi, T., Weinberger, R., Aïfa, T., Eyal, Y., S. Marco, S. 2006b. Earthquake-induced clastic dikes detected by anisotropy of magnetic susceptibility, Geology, 34(2), 69-72.

Levi, T., Weinberger, R., Eyal, Y., Lyakhovsky, V., Hefez, E. 2008. Velocities and driving pressures of clay-rich sediments injected into clastic dykes during earthquakes. Geophysical Journal International 175, 1095-1107. Levi, T., Weinberger, R., Alsop, G.I., Marco, S. 2018. Characterizing seismites with anisotropy of magnetic susceptibility. Geology 46 (9), 827-830.

Lu, Y., Waldmann, N., Alsop, G.I., Marco, S. 2017. Interpreting soft sediment deformation and mass transport deposits as seismites in the Dead Sea depocentre. Journal of Geophysical Research: Solid Earth, 122. 10, 8305-8325. Doi: 10.1002/2017JB014342.

Marco, S., Stein, M., Agnon, A., and Ron, H., 1996. Long term earthquake clustering: a 50,000 year paleoseismic record in the Dead Sea Graben: J. Geophys. Res., 101, 6179-6192.

Martinsen, O.J., Bakken, B. 1990. Extensional and compressional zones in slumps and slides in the Namurian of County Clare, Ireland. Journal of the Geological Society, 147, 153-164.

Migowski, C., Agnon, A., Bookman, R., Negendank, J.F.W., and Stein, M., 2004, Recurrence pattern of Holocene earthquakes along the Dead Sea transform revealed by varve-counting and radiocarbon dating of lacustrine sediments: Earth and Planetary Science Letters, v. 222, p. 301-314.

McClay, K.R., 1992. Glossary of thrust tectonic terms. In: McClay, K.R. (Editor) Thrust Tectonics. Chapman and Hall, London. P. 419-433. 
Morley, C.K., King, R., Hillis, R., Tingay, M., Backe, G. 2011. Deepwater fold and thrust belt classification, tectonics, structure and hydrocarbon prospectivity: A review. Earth Science Reviews, 104, 41-91.

Moscardelli L., Wood L. 2008. New classification system for mass transport complexes in offshore Trinidad. Basin Res 20:73-98. doi: 10.1111/j.1365-2117.2007.00340.x

Nuriel,P., Weinberger, R., Kylander-Clark, A.R.C., Hacker, B.R., Cradock, J.P. 2017. The onset of the Dead Sea transform based on calcite age-strain analyses. Geology 45, 587-590.

Ortiz-Karpf, A., Hodgson, D.M., Jackson, C, A-L., McCaffrey, W.D. 2018. Mass-transport complexes as markers of deep-water fold-and-thrust belt evolution: insights from the southern Magdalena fan, offshore Colombia. Basin Research 30, 65-88. doi: 10.1111/bre.12208

Palladino, G., Grippa, A., Bureau, D., Alsop, G.I., Hurst, A. 2016. Emplacement of sandstone intrusions during contractional tectonics. Journal of Structural Geology 89, 230-249.

Porat, N., Levi, T., Weinberger, R. 2007. Possible resetting of quartz OSL signals during earthquakes - evidence from late Pleistocene injection dikes, Dead Sea basin, Israel. Quaternary Geochronology2, 272-277.

Posamentier, H.W., Martinsen, O.J. 2011. The character and genesis of submarine mass-transport deposits: Insights from outcrop and 3D seismic data. Mass transport deposits in Deepwater settings: Society for Sedimentary Geology (SEPM) Special Publication 96, 7-38.

Prasad, S., Negendank, J.F.W., Stein, M. 2009. Varve counting reveals high resolution radiocarbon reservoir age variations in palaeolake Lisan. Journal of Quaternary Science 24, 690-696.

Ramsay, J.G. 1974. Development of chevron folds. Geological Society of America Bulletin 85, 1741-1754. Reis, A.T., Araújo, E., Silva, C.G., Cruz, A.M., Gorini, C., Droz, L., Migeon, S., Perovano, R., King, I., Bache, F. 2016. Effects of a regional décollement level for gravity tectonics on late Neogene to recent large-scale slope instabilities in the Foz do Amazonas Basin, Brazil. Marine and Petroleum Geology 75, 29-52.

Scarselli, N., McClay, K., Elders, C. 2016. Seismic geomorphology of Cretaceous megaslides offshore Namibia (Orange Basin): Insights into segmentation and degradation of gravity-driven linked systems. Marine and Petroleum Geology 75, 151-180.

Shillington, D.J., Seeber, L., Sorlien, C.C., Steckler, M.S., Kurt, H., Dondurur, D., Cifci, G., Imren, C., Cormier, MH, McHugh, C.M.G., Gurcay, S., Poyraz, D., Okay, S., Atgin, O., Diebold, J.B. 2012. Evidence for widespread creep on the flanks of the Sea of Marmara transform basin from marine geophysical data. Geology 40, 439-442.

Sneh, A., Weinberger, R. 2014. Major structures of Israel and Environs, Scale 1:50,000. Israel Geological Survey, Jerusalem.

Sneh, A., Rosensaft, M. 2019. Geological Map of Israel, scale 1:250,000. Geological Survey of Israel, Jerusalem Sobiesiak, M., Kneller, B.C., Alsop, G.I., Milana, J.P. 2017. Sub-seismic scale folding and thrusting within an exposed mass transport deposit: A case study from NW Argentina. Journal of Structural Geology 96, 176-191.

Steventon, M.J., Jackson, C,A-L, Hodgson, D.M., Johnson, H.D. 2019. Strain analysis of a seismically imaged masstransport complex, offshore Uruguay. Basin Research 31, 600-620.

Stewart, S.A., Argent, J.D. 2000. Relationship between polarity of extensional fault arrays and presence of detachments. Journal of Structural Geology 22, 693-711.

Syvitski, J.P.M., Burrell, D.C., Skei, J.M. 1987. Fjords: Processes and Products. Springer-Verlag, New York. Tanner, P.W.G. 1989. The flexural-slip mechanism. Journal of Structural Geology 11, 635-655.

Twiss, R.J., Moores, E.M. 2007. Structural geology. $2^{\text {nd }}$ edition. W.H. Freeman and Company. New York. 736pp. Watterson, J., Childs, C., Walsh, J.J. 1998. Widening of fault zones by erosion of asperities formed by bed-parallel slip. Geology 26, 71-74. 
942 Weinberger, R., Begin, Z.B., Waldmann, N., Gardosh, M., Baer, G., Frumkin, A., Wdowinski, S. 2006. Quaternary 943 rise of the Sedom diapir, Dead Sea basin. In: New Frontiers in Dead Sea Paleoenvironmental Research, (Enzel, Y. 944 Agnon, A., Stein, M., eds). Geol. Soc. Am. Special Paper, 401, 33-51

945 Weinberger, R., Levi, T., Alsop. G.I., Eyal, Y. 2016. Coseismic horizontal slip revealed by sheared clastic dikes in 946 the Dead Sea basin. Geological Society of America Bulletin 128, 1193-1206.

947 Weinberger, R., Levi, T., Alsop. G.I., Marco, S. 2017. Kinematics of Mass Transport |Deposits revealed by magnetic 948 fabrics. Geophysical Research Letters 44, 7743-7749.

949 Zalan, P.V., 2005. End members of gravitational fold and thrust belts (GFTBs) in the deep waters of Brazil. In: 950 Shaw, J.H., Connors, C., and Suppe, J., (Editors) An AAPG Seismic Atlas: AAPG studies in Geology 53, 147-156.

951 Zucker, E., Frumkin, A., Agnon, A., Weinberger, R. 2019. Internal deformation and uplift-rate of salt walls detected 952 by a displaced dissolution surface, Dead Sea basin. Journal of Structural Geology 127, 103870. 